\title{
Foreign Languages in the Educational Space of Southern Federal University of Russia
}

\author{
Irina Eduardovna Kulikovskaya ${ }^{1}$, Lubov Vitaljevna Abdulmanova ${ }^{1} \&$ Anna Vladimirovna Reznichenko $^{1}$ \\ ${ }^{1}$ Southern Federal University, Rostov on Don, Russia \\ Correspondence: Irina Eduardovna Kulikovskaya, Bolshaya Sadovaya Str., 105/42, Rostov-on-Don, 344006, \\ Russian Federation.
}

Received: February 28, 2015 Accepted: March 20, 2015 Online Published: April 24, 2015

doi:10.5539/res.v7n6p162

URL: http://dx.doi.org/10.5539/res.v7n6p162

\begin{abstract}
The authors have revealed the concept of educational space as a set of objective-subjective components, including regulatory and legal requirements for higher professional education, scientific-theoretical bases of professionally-oriented world-view of students, the totality of the content and technologies of teaching and education, individual and creative environment of self-development of the students. There have been identified the key characteristics of the Federal University: tendency to the world educational space; expansion of the range of educational services and research; the integration of scientific and educational activities; intensive development of intellectual capital and commercialization of scientific achievements. The Mission of Southern Federal University in Russia has been defined as preservation and development of scientific and educational environment for the formation of citizens who are able to serve Russia and the entire world to the best. The role of foreign languages in the formation of local and meta-educational space of Southern Federal University has been proven.
\end{abstract}

Keywords: educational space, teaching of foreign languages, Southern Federal University

\section{Introduction}

\subsection{Introduce the Problem}

Beginning of the 21 st century was marked by a trend of considering poly-lingual education as a basis for preserving of the linguistic heritage and cultural diversity of humanity. This "century introduces certain corrective amendments into the developed over several thousand years, assumptions about the content and methods of interaction, since the development of the information society changes the values of dialogue" (Kulikovskaya, 2013). Modern students are Internet-generation, they are undergoing the rapid evolution of the brain, improve their IQ, develop multi-tasking and cognitive abilities. A side effect of this "digital evolution" of the brain, according to G. Small and G. Vorgan, is the isolation of the individual from society, and the sudden emergence of a new relationship between people is becoming a rarity. "A Stanford University study found that for every hour we spend on our computers, traditional face-to-face interaction time with other people drops by nearly thirty minutes" (Small \& Vorgan, 2008).

Therefore, there arises a necessity of forming of a poly-lingual picture of the world in the younger generation, which provides the establishment of a new language of thinking, of the awareness of the need to learn the language of the titular nation (in the Russian Federation-Russian), the sense of unity with the human culture and readiness for continuous professional development of language training in a professional career. These trends are of particular importance in the context of globalization, with the emergence of "organic solidarity", integration and cooperation, which involves the ability to understand each other. Essential to the understanding of another culture is to master the forms, and above all, the language that provides the opportunity to competently review the most important professional and personal information, and its adequate perception and interpretation. This causes increased requirements to quality of understanding of the language used by the partner. L. R. Ismagilova says that the mastering of different languages is becoming a prerequisite for a successful life in the modern world, and poly-linguism is required for successful adaptation to social and professional environment (Ismagilova, 2005). 


\subsection{Explore Importance of the Problem}

The phenomenon of educational space has been investigated in scientific since relatively recent times. In various sources one can find quite similar concepts: "educational space" and "educational environment". Educational space is often spoken about as an environment for human development, although the terms "space" and "environment", in our view, can be easily enough separated. Drawing on research of E. V. Bondarevskaya, V. P. Borisenkov, A. Y. Danyluk, O. V. Gukalenko, G. A. Kovalev, A. Berlant, D. Gold, J. Gibbson, V. I. Kaznacheev, U. A. Urmancev, we have formulated definitions of these terms in the context of our study. Educational space is a set of objective-subjective components, including regulatory and legal requirements for higher education, scientific-theoretical bases of professionally-oriented world of students, the totality of the content and technologies of teaching and education, individual and creative environment for self-development of the students. Designing of educational space refers to a technique of pedagogical support of the professional development of students, which allows a purposeful, consistent, gradual providing of educational content, opening the world of the future profession. Characteristics of educational space are contained in the concept of development of the institution and educational program that combines regulatory requirements and the results of the innovative search of educators.

Educational environment is the subjective part of the educational space and takes into account the sensory-perceptive human organization (Ananiev, 1969), mechanisms of emotion (Vasiluk, 1984), and reasons of professional formation of students. The main role in establishing educational environment belongs to the pedagogical team. Its components are: the subject (all available options for enhancing sensory-perceptual channel of perception and motor activity); the emotional-sensual (all possible options to enhance the emotional-sensual channel of perception and cognition); the intellectual; the social (the ability to experience independent of social contacts of different plan, i.e., not only with fellow students, but also with teachers and future employers); the creative (conditions for free creativity).

Close to the notion of "space of personal self-development" is the term "individual educational space" (Borisov, 1999). Individual educational space is defined as a field of social activity of personality and education and is characterized by the following qualities:

Multidimensionality, which includes spiritual, social, physical, internal and external components of the student's world;

The integrity of the student perception in the system of multifactor interaction, performing various functions in his life;

Reflection of subjective position of the child in terms of educating the individual as personal and social type;

Technology that can not only explain and describe the schoolboy's world, but design it (Borisova, 1999).

T. F. Borisova considers the educational space as a factor of social education of students, as real space-time continuum of certain relations in the sphere of the contents and organization of education, based on real information and directive framework, as well as organized, sustained interaction of the individual with open social and educational environment.

Development of modern educational space is associated with the inclusion of modern means of communication. In this regard, the term "information space of an educational institution" has been introduced into the studies. Considering the information and educational space of the Pedagogical University, V. I. Bogoslovskiy, V. A. Izvozchikov, M. N. Potemkin et al., have proven that the methodology of its construction and development should be based on the following principles:

1) Computerization of educational process and of its supporting organizational processes (creation of the technical complex that includes personal computers and peripherals, the educational and administrative-managing computer networks connected to the global information space-Internet, and based on it enterprise systems of management and learning);

2) Informatization of educational process (creation and use of the information and the abstract-model spaces to allow major participants of the pedagogical process effectively exercise their functions in accordance with the strategic goals and objectives of the professional development of a specialist in today's society of, global information and mass communication) (Bogoslovskiy et al., 2000).

Information and educational space in the informational civilization acquires the characteristics of information system management process, which is built in accordance with such cyber criteria as focus, performance, profitability, self-learning, based on clear feedback et al. Information technology has become the basis of design and simulation of a new educational environment and educational space (Branovskiy et al.). Educational space 
can be viewed from the perspective of interaction between three participants: teachers, pupils and the environment among them. L. S. Vygotsky idea of triangular active process (active teacher, active student, active environment between them) allows to represent the interaction of educational space as a single process of purposeful development of the person of a student. Interaction of participants of the educational space leads to the formation of the "environment of common activity", its "exclusion" from them, turning it into a subject of an educational space. It results in the formation and execution of objectives, motivations, methods of professional formation of University students.

In the Rostov school of Professor E. V. Bondarevskaya the features of student-centered educational space are defined by the capacity to fully meet the needs of cultural development, socialization and education of children and youth. The author examines the notion of integrated educational environment, in which tasks of education are fulfilled by cooperative mutual efforts of educational institutions, while preserving its specificity and autonomy. Integrated type of relationship among the educational institutions suggests their merging in a coherent social and State structure. In her research Professor E. V. Bondarevskaya gives definition of the educational environment as culturally appropriate environment of upbringing of a cultural and moral individual. The notion of "culturally appropriate environment" is understood as the environment, epicenter of which is a personsovereign, free, capable of free choice of samples of cultural life and creativity. In this environment, everyone can apply their strength, creativity, meet their interests, found the necessary environment for a dialogue, kind and sincere attitude on the part of adults and peers (Bondarevskaya, 2007).

Theory of integral humanitarian spaces as education systems of person-developmental type is developed in the study A. Danyluk. In the field of humanitarian education it distinguishes two kinds of educational spaces: culturological (local) and the culturally appropriate meta-educational space. Local space includes a limited number of subject languages - two, and, as a rule, no more than three. For meta-space there are no such restrictions. All languages of humanity disciplines can be represented in it, and it is open to new processes of differentiation and integration. In our research we study both local, and meta-educational space of Southern Federal University, which includes discipline training, as well as the substantive content of the extracurricular activities (Daniluk, 2000).

The most varied and holistic theory of educational space is given in the monograph of V. P. Borisenkov, O. V. Gukalenko, A. Danyluk "Multicultural Educational Space in Russia: History, Theory, Principles of Design. the most important for us was the idea that the free development of personality involves its free movement in the world of different cultures, self-determination not only in small (native), but also in the big world. Cultures develop in a dialogue space, ensuring their interaction and self-determination of personality in world culture. Personalization and customization of the process is aimed at restructuring the value of semantic characteristics of professional picture of the world. This process leads to the development of the human world as a visible image of the universe and oneself as a professional, competent (Borisenkov et al., 2004).

\section{Methods}

We examined the dynamics of poly-lingual picture of the World of South Federal University students based on criteria and indicators developed by us: axiological, semeiological, perspective, and reflexive.

To determine axiology as a criterion of poly-lingual picture of the world, modification techniques of Dembo-Rubinstein for self-evaluation by placing oneself on the scale have been used. Self-evaluation scale included both professionally meaningful and general personal qualities, which helped to determine their place and value in the structure of self-evaluation of professionally significant qualities.

Identification of semeiology of poly-lingual picture of the world of students was carried out in the process of writing their essay "My Future Profession in the World Space". Professional vocabulary and its representation in different languages were evaluated.

Examination of the prospects of the study of foreign languages, i.e. perceptions of the need for continuous professional learning in connection with new developments in technology and changes in the socio-cultural reality, was carried out by the method of a test.

Identification of reflexivity, i.e. reflection, realization of the existing level, of the prerequisites and prospects for professional development was carried out by the method of a talk.

Formation of a poly-lingual picture of the World of University students is a process of development of Russian and foreign professional cultures, of gaining experience of interaction with foreign counterparts on the basis of verbal and non-verbal means, of adding of sets of meanings behind a certain concept in different languages, as well as the acquisition of new concepts and idioms, actively used in the world professional vocabulary. 


\section{Results}

Development of the educational space in Russia is connected with the creation of Federal universities (2007). This is the phenomenon, indicating the future shape of the country, the main directions of its development, and the improvement of competitiveness at world level. That is why strengthening the scientific, educational and industrial and technological relations with foreign countries is one of the most important tasks of the Federal universities. The research process in such institution is integrated with education, creating a new quality of student training. The University has become the center of the influence on the innovation development of the region, of the improving security and competitiveness in global markets of knowledge and technologies.

When organizing the Federal universities, Russia focused on world experience, because these universities were established in many countries. The quality of European education, with a rich history of development, continues to receive international recognition. United Kingdom reaffirmed the status of World Education Center: thirty-two of the best universities in the world are situated here. Oxford and Cambridge universities are competing with the United States. Among the fifty "most-most": London School of Economics, Imperial College London, University of Manchester, School of Oriental and African Studies and the University of Edinburgh. One of the best schools in Europe is in Switzerland. Swiss Federal Institute of Technology in Zurich, where Albert Einstein studied, is one of the leading universities in the world.

Quality education in today's world you can get both in the United States and in Europe, in Asia and in Australia, where science is growing, modern education programs are developing, where there is the integration of science and education. To meet the challenges of entering the rating of the leading universities of the world and identify ways to innovative development of the Russian Federation is the task of National Research and Federal universities. The Russian Government declares a strategy of transition to innovative economy, and this is linked to the growing complexity of the tasks and their decision on the basis of new knowledge, which must find its expression in innovation. In these circumstances, the Federal universities should play a leading role in the development of innovative society, should become a part of a global innovative society, means and form of integration of the three elements of the knowledge triangle (education, research and innovation).

\section{Discussion}

Strategic leadership philosophy of the Federal University is the foundation of the ideology changes taking into account the challenges of modern society. One of the world's mega trends is to create a knowledge-based economy. "New, bright, promising ideas, setting new goals, algorithms for their implementation, new technologies and business models are a source of income" (Serbinovskiy \& Ozdoeva, 2010). That is why the professionals are the highest value of any enterprise or organization. These professionals must be willing to work in the world, the relations between the development and use of new knowledge, the integration of education, and scientific data in their professional activities. Federal universities occupy a leading position in this. They accumulated highly qualified staff that is able to perform complex interdisciplinary research and design work for companies and organizations. Their material equipment, scientific, applied and theoretical base for conducting qualitative research are also very important.

B. Y. Serbinovskiy argues that the most important place in the strategy of the University can and should take the strategy of intellectual leadership. This strategy is essential to competition, evaluation of the results of individual activities both the teachers and students, increasing of knowledge and skills. In the conditions of knowledge economy grows this special area as knowledge enterprise, which is formed in the Federal universities and suggests the integration of science and production.

Here is an example of educational space of Southern Federal University, which is the base of our research. The Mission of the University is maintaining and developing of scientific and educational environment for the formation of citizens able to serve Russia and the whole world in the best way (http://sfedu.ru). The strategic objectives, in particular, include: addressing the needs of the individual in the intellectual, moral and cultural development through higher and postgraduate education; the innovative nature of its educational, scientific, and socio-cultural activities; competitiveness in the world markets of scientific development and educational services; raising individuals capable of self-organization, self-education, able to engage in constructive dialogue, seek and find meaningful compromises et al. These objectives clearly do not include poly-lingual picture of the world of professionals, but it is a necessary condition for the decision of the set tasks, aimed at the leadership in the world space (Kulikovskaya \& Ovsepian, 2012).

Innovative Federal University has to acquire new forms and means of transferring knowledge and technologies. Here we see the important role of foreign languages both for the teachers and the students, which will create new incentives for self-realization in science and knowledge economy. In the modern world the ability of Federal 
universities graduates to be quickly incorporated in international competition is a key indicator of the quality of higher education. International mobility is increasing, and this fact immeasurably increases the role of foreign language, which today is one of the main criteria for employment, and also serves as a competitive advantage. Students have been eager to learn more foreign languages recently.

The acquisition of a foreign language competence is performed in the local educational space that is organized in one lesson by coordinating of 2-3 humanities. Foreign Language here is compulsory, and materials of History, Culturology, Sociology, Pedagogy or other disciplines are considered as a system of knowledge, additional to Foreign Language content, provided by the curriculum. Students have been eager to learn several foreign languages recently. Giving them that opportunity, the University creates a new meta-educational area, carrying out a systematic synchronization of core academic subjects (Foreign Languages, History, Literature, Culture of Art, Philosophy et al.). A flexible system of local spaces is organized in it. Traditionally, the international language is English, but in cooperation with European companies business contacts are established on the language of partners: advantage have French, German, Spanish, and Italian.

Therefore many students, who want to make a career, do not miss the opportunity to learn the second, third and even fourth foreign language. One of the most important priorities of Southern Federal University is academic mobility of students supported by State and regional programs. Student Exchange is seen as a powerful means of developing global market expertise and high-quality workers. There is a spontaneous move of students independently of any programs. This is because their professional and cultural needs make educational programs of many countries of the world attractive for them.

In such a situation, formation of poly-lingual picture of the world is one of the actual problems of modern higher education and of the students. In addition to the European languages demand for the Chinese language also glows -cooperation of Russian companies with the largest country in Asia is gaining momentum with each passing year. Along with the mastering of "traditional" European languages there needed specialists who know Hebrew, Portuguese, Hindi. And in recent years interest in Czech, Polish, Slovak and Scandinavian languages: Finnish, Swedish group, Norwegian has significantly increased.

Formation of the poly-lingual world view of students depends on such fundamental issues as the organization of educational process: focus on the learner's personal qualities (Grigoryev, Grishkun, \& Sheluhina); refusal from the traditionally dominant form as monologue training activities and the development of dialogue training activities (communication, talk, discussion); understanding of foreign language communication not only as the ability to translate information in the structure and forms of a foreign language, but also encourage the partner to any action of speech or non-verbal activity, as well as the realization of the speaker's self-actualization (Polat \& Rahmanov).

Learning of a foreign language should not be an aim in itself but rather a means of achieving the goal of raising of the education level within a narrow specialty. Since the Federal University aims to develop the intellectual capital of the country and the region, studying a foreign language is a means of self-actualization, career involvement in innovative international process characterized by the logical chain: innovation-advanced technologies- new economy (knowledge economy). An interesting tendency, in our opinion, is to use the foreign language classes in non-language Universities of the ethnographic commentary (Skroznikova, Bodankina, et al.). Ethnographic material is regarded as a form of realization of interdisciplinary links. The authors noted that the brief comments of the ethnographic or lingual-ethnographic nature reveal communications of practice of foreign language teaching with the content of the programs of other disciplines and have a positive effect on the acquisition of non-language universities students' deeper knowledge (Skroznikova \& Bodankina, 1978).

Accepted technology for teaching foreign languages is now a communicative orientation of the educational process. The scientists of the Institute of Russian Language named after Alexander Pushkin worked at the development of communicative directions (Leontjev et al.). The communicative method is aimed at training speaking, since the method is based on the similarity of the learning process and the communication process. E.I. Passov has formulated the following principles of communicative learning (Passov, 1989):

1) The principle of speech-thinking activity involves the organization of learning when a student is involved in the process of communication. The practical speech is both a focus, and a learning tool. According to this principle the basis of communicative learning content is its problematic character. For the organization of the process of learning to communicate it is necessary to select those problems and problem situations, which can intensify the contractures and cause the need for discussion.

2) Principle of individualization of learning, i.e., considering of all properties of a trainee as a personality: his abilities, abilities to exercise voice and training activities and primarily his personal properties. Communication 
is always individually, always painted and due to all the human personality traits: individual, subjective and personal. Individualization is the real way to build motivation and activity.

3) Principle of functionality requires functional selection and organization of speech. Functionality means that any unit of speech, any language form is performing some speech functions in the process of communication. In learning to communicate in a foreign language learners are not able (limited hours) to assimilate the entire speech in full. Therefore, you must create a functional model of the system that is simplified, minimized, but could functionally replace the whole system of speech means.

4) The principle of contextuality requires recognition of a situation as a unit of foreign language learning communication. Situational context is able to recreate the communicative reality and thus initiate the interest by the authenticity of speaking. The situation in the communicative speech provides presentation of material, the formation of speech skills, and it is the basis of speech units.

5) The principle of novelty covers the whole learning process, and it is extremely important for the success of communicative teaching. The process of communication is characterized by constant change of the subject of conversation, circumstances, conditions, tasks et al. Novelty provides the necessary development of speech skills, particularly its dynamism, ability to paraphrase, a mechanism of combining, creativity of the speech, pace of speech and, in particular, the strategy and tactics of the speaker.

The principles of teaching communicative interaction, defined by E. I. Passov, make it possible to imagine the system of foreign language communication. The author proves that foreign languages should be taught only through communication, as they are one of the ways of realization of educational, informative and educational training purposes. The modern concept of foreign language teaching in high school aims at establishing of a complete basic standard and is communicative in its purpose and technology of training, cognitive development, personality-based and differentiated in its content and teaching methods.

In recent years in the theory and practice of professionally-oriented teaching of foreign language in high school, great attention is paid to issues related to using it as a communication tool in the dialogue of cultures and civilizations in the modern world (Bim, et al.). Communicative and socio-cultural development of students by means of the subject "Foreign Language" is largely due to properly implementation of lingual-ethnical approach. This approach provides language acquisition in close liaison with foreign culture, which includes a variety of educational information about history, literature, architecture, everyday life, customs, and way of life and traditions of the people of the country of the studied language. Attraction of cultural information raises the motivation of students' learning, which is of the utmost importance, since without motivation teaching is ineffective.

Socio-cultural approach in teaching foreign languages is based on the following principles:

1) The principle of didactic cultural conformity. According to this principle certain rules are necessary in the selection of facts:

- Define the value sense and value relevance of selected materials for the formation of students' undistorted view of the history and culture of the studied peoples;

- To understand the extent to which the learning material can serve as an incentive for studying the concept of "cultural heritage", "cultural community", "cultural diversity", "language and language culture" et al.

2) The principle of dialogue among cultures and civilizations. This principle draws attention to the need to analyse the cultural authentic material in terms of its potential use in the student audience. This principle also implies that in the process of formation of cultural space in the foreign language communication there used literary material of the home country.

3) The principle of the domination of methodically acceptable cultural problem tasks guides the teacher to building such a model of learning, where students are:

- Training in the collection, collation, synthesis and interpretation of cultural information;

- Mastering the strategies of cultural search and the means of cultural interpretation;

- Taking part in creative activities of cultural character.

At present time when professional and personal contacts with teachers and students from different countries are increasing, the socio-cultural context of learning a foreign language is especially important. But it is necessary to take into account the fact that the knowledge of a foreign language at present is not only the cultural development of a specialist, but also one of the conditions of their successful career. 
Creative technologies of active learning have been widely used recently (Alfyorov et al.). Application of these technologies ensures the development of creative abilities of the future specialists and has implications for the formation of their poly-lingual picture of the world in the educational space of the university. The leading become active methods of teaching material and of working in the training group. In accordance with this type of activity the role of both teacher and students is changing. The students become equal participants in solving professional problems by getting the required support and assistance from the teacher.

Much attention in today's higher education is paid to the quality of students' education. The study of O. I. Safronenko is carried out in this context. The author identifies key principles for ensuring the quality of language training of non-language universities student, develops a conceptual model of multilevel system of language training of students, develops diagnostic techniques of assessment, on the basis of which there is a system of monitoring of the quality of language training of students. For our study of the significance is the thought of the scientist that the modernization of language training should be based on the transition to a system of multilevel education and implementation of high-quality language training, in line with international standards, through the review of the goals and objectives of the study, based on the requirements of the labour market and appropriate focus (domestic, academic, scientific and professional) (Safronenko, 2006). We have worked out the content of the development process of a poly-lingual world view of students, relying on this idea. That is why the content of special courses is updated. It contains not only the vocabulary, related to the future profession, but also to household sphere.

Not by accident the notion of linguistic identity (Karaulov) as a set of linguistic competence and speech skills of the individual has appeared in recent years and has become widely spread: it is the formation of the modern linguistic personality that is made the corner-stone of teaching disciplines language cycle. Of paramount importance is the communicative orientation of the training, reflecting the changing priorities of education, improving its practical orientation. The result, according to modern standards of learning, is fluent Russian language in the professional activity of graduates of Southern Federal University (Karaulov, 1987).

In a knowledge economy, the process of education, teaching, learning is a process of continuous and informal character. The traditional transfer of experience and skills in the teaching of foreign languages turns into new technologies of "cross-training", dipping the poly-lingual environment, i.e., meta-educational space, when students spread the boundaries of their professional consciousness in the process of exploring other cultures. An important novelty is the language of openness, implying the destruction of language barriers, removing the psychological tension when dealing with professionals who live in other countries (Harmon, 1995; Maffi, 1998; Williams, 1998; Daniel, 2011).

\section{Conclusion}

Thus, the analysis of research enabled us to identify the main characteristics of Federal University: the tendency to enter the world educational space; expansion of the range of educational services and research; the integration of scientific and educational activities; intensive development of intellectual capital and commercialization of scientific achievements. Federal universities, created in the Russian Federation, are called to perform one of the most important missions - to enter into the global educational space, and into the rating the world's leading universities. To this goal the development of corporate culture, modernization of the educational process, introduction of a philosophy of constant change is devoted. In Southern Federal University conditions are created for professional and personal self-development of students, their willingness to work in the world. The decision of such ambitious tasks in many respects depends on attracting foreign students and academic mobility of students studying certain courses in foreign universities. Accordingly, the main objective of the language training of students in high school becomes formation of their poly-lingual picture of the world, which opens up the possibility of cooperation in the world space thanks to the professional ability to extract enough information while reading foreign-language texts, the willingness to understand colleagues from other countries, as well as to express their point of view on professional issues.

\section{Reference}

Ananiev, B. G. (1969). Individual as an object of cognition. Leningrad.

Bogoslovskiy, V. I., Izvoschikov V. A., \& Potemkin, M. N. (2000). Science in Pedagogical University: Issues of methodology, theory and practice. St. Petersburg.

Bondarevskaya, E. V. (2007). Value Basis of Personality-Oriented Education. Pedagogy, 8, 44-53.

Borisenkov, V. P., Gukalenko, O. V., \& Daniluk, A. Y. (2004). Multicultural Educational Space in Russia: History, Theory, and Principles of Design. Rostov on Don: Rostov State Pedagogical University. 
Borisova, T. F. (1999). Educational Environment as a Factor of Social Education of Students (PhD thesis). Moscow: Institute of Pedagogy of Social Work.

Daniel, G. (2011). Our Many-Sided World: Linguistic, Cultural and Biological Diversity of the Planet. In Terralingva and World-Wide Fund of Nature, UNESCO. Retrieved from http://www.terralingua.org/wp-content/uploads/downloads/2011/01/RussianWOD.pdf

Daniluk, A. Y. (2000). Theory of Integration of Education. Rostov on Don: Rostov State Pedagogical University.

Harmon, D. (1995). The status of the world's languages as reported in Ethnologue. Southwest Journal of Linguistics, 14, 1-33.

Ismagilova, L. R. (2005). Poly-linguism as a Component of Economic Culture ( $\mathrm{PhD}$ thesis). Kazan: Kazan State Institute of Finance and Economy.

Karaulov, Y. N. (1987). Russian Language and Linguistic Personality (p. 263). Moscow: Science Publishing.

Kulikovskaya, I. E., \& Ovsepian, Y. Y. (2012). Formation of a Poli-Lingual Ppicture of the World in University Students. LAP LAMBERT Academic Publishing.

Kulikovskaya, I. E. (2013). Axiological Sphere of Dialogue of Cultures: Phenomenon, Architectonics, Ontogenesis. World Applied Sciences Journal, 25(10), 1416-1422.

Maffi, L. (1998). Language: A Resource for Nature and Ressources. The UNESCO Journal on the Environmental and Natural Resources Research, 34(4), 12-21.

Passov E. I. (1989). Bases of Communicative Teaching Methodology of Foreign Language Communication Teaching (p. 276). Moscow: Russian Language.

Safronenko, O. I. (2006). System and Quality of Language Training of Students in the Non-Language Universities of Multilevel Education in Russia (PhD thesis). Rostov on Don: Rostov State University.

Serbinovskiy, B. U., \& Ozdoeva, A. M. (2010). The Strategy of a New Type of University Intellectual Leadership in the Market of Educational and Scientific Services (p. 14). Novocherkassk: SRSTU (NPI).

Skroznikova, V. A., \& Bodankina, R. N. (1978). Ethnical Comment as one of the Forms of Inter-subject Links. Foreign Languages in High School, 13, 113-116.

Small, G. \& Vorgan, G. (2008). iBrain: Surviving the Technological Alteration of the Modern Mind. New York, London, Toronto, Sydney: Harper.

Vasiluk, F. E. (1984). Psychology of Emotions (analysis of overcoming critical situations (p. 200). Moscow: Moscow University Publishing.

Williams, E. (1998). Investigating Bilingual Literacy: Evidence form Malawi and Zambia. In Education Research (Vol. 24). London: Department for International Development.

\section{Copyrights}

Copyright for this article is retained by the author(s), with first publication rights granted to the journal.

This is an open-access article distributed under the terms and conditions of the Creative Commons Attribution license (http://creativecommons.org/licenses/by/3.0/). 